\title{
Quantification of isonicotinoyl lactosyl hydrazone in oral pharmaceutical dosage forms
}

\author{
D. Córdoba-Díaz ${ }^{\text {a,* }}$, M. Córdoba-Díaz ${ }^{\mathrm{a}}$ and B. Elorza ${ }^{\mathrm{b}}$ \\ ${ }^{a}$ Department of Pharmacy and Pharmaceutical Technology, Faculty of Pharmacy, Complutense \\ University of Madrid, Madrid, Spain \\ ${ }^{\mathrm{b}}$ Department of Physical Chemistry, Faculty of Pharmacy, Complutense University of Madrid, Madrid, \\ Spain
}

\begin{abstract}
Isoniazid, one of the most important drugs for the chemotherapy of tuberculosis, can react with some widely used pharmaceutical excipients, like lactose, leading to the formation of hydrazones. This interaction can dramatically modify the oral bioavailability of the drug, what could lead to a failure of the treatment. Some analytical methods, including techniques like HPLC, can be used to quantify this type of products, but all of them are tedious and time-consuming. In this sense, the aim of the present work is to develop a sensitive, rapid and cheap alternative to other published methods. For this reason, two spectrophotometric methods were developed and validated. In the first one, isoniazid and its lactosyl-hydrazone were measured together. The second one involved a reaction between not bound to lactose isoniazid and 2,3-dichloro-1,4-naphthoquinone. Lactosyl-hydrazone is quantified by comparison of the results obtained from both methods. The linearity is confirmed to be within a range of $1.5-30.0 \mu \mathrm{g} / \mathrm{ml}$ of total isoniazid and $0.5-30.0 \mu \mathrm{g} / \mathrm{ml}$ of "free" isoniazid. Limits of quantification of $1.2 \mu \mathrm{g} / \mathrm{ml}$ and $0.3 \mu \mathrm{g} / \mathrm{ml}$ were obtained for bound and free isoniazid respectively. These results indicated that the here described methods are at least, as sensitive and accurate as the vast majority of the previously published chromatographic methods. This methodology shows a good repeatability (RSD below 2.0\%) as well as good accuracy (average recoveries of 100.83\% and 99.96\% for total and free isoniazid respectively). The results obtained from the assay of isoniazid tablets demonstrated that the proposed method constitutes a clear alternative to chromatographic methods and also to the official titration method. It would be of interest for the routine quality control of oral dosage forms containing isoniazid and lactose and for stability studies.
\end{abstract}

Keywords: Isoniazid, assay, lactosyl-hydrazone, validation, UV-Vis spectrophotometry, derivatization

\section{Introduction}

Tuberculosis has been defined as the most important infection disease in all over the world. The treatment of tuberculosis has become an even more important and challenging problem because of the acquired immunodeficiency syndrome pandemic and migratory movements [1,2]. Isoniazid (INH), chemically isonicotinic acid hydrazide, is one of the first line agent for the primary and secondary treatment of tuberculosis $[3,4]$ and hence, many attempts have been made to develop methods for its quantification in pharmaceutical dosage forms in the presence of different excipients [5-8].

\footnotetext{
*Corresponding author: Prof. Dr. Damián Córdoba-Díaz, Dpto. de Farmacia y Tecnología Farmacéutica, Facultad de Farmacia, Universidad Complutense de Madrid, Pza. de Ramón y Cajal s/n, E-28040, Madrid, España. Tel.: +34 9139472 43; Fax: +34 9139417 36; E-mail: damianco@ farm.ucm.es.
} 


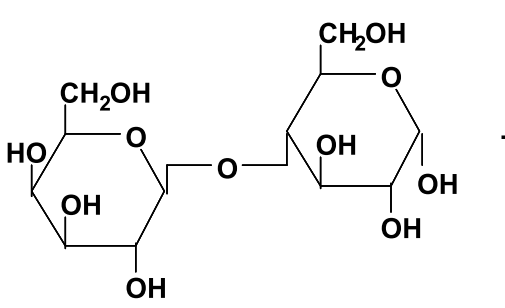

LACTOSE

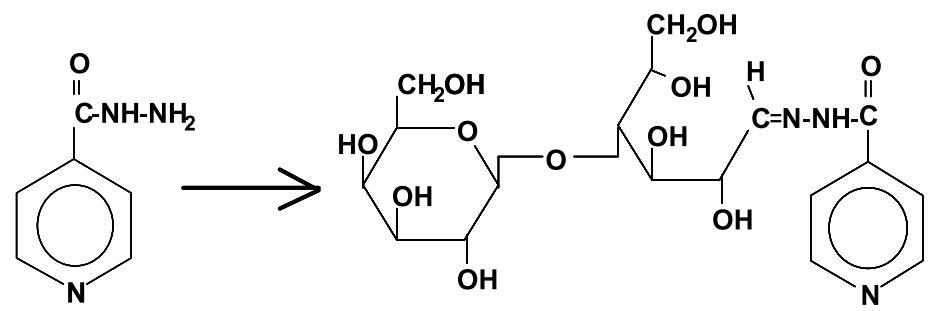

LACTOSYL-HIDRAZONE

Fig. 1. Scheme showing the interaction mechanism INH - lactose in solid dosage forms leading to the formation of 1-isonicotinyl-2-lactosylhydrazine.

From a technological point of view, lactose is a free flowing, highly compressible powder that is widely used as filler in tablet and capsule formulation [9]. In this way, it has been observed that most of the commercially available INH tablets included lactose as main excipient.

It has been reported by many authors that INH can interact with lactose in solid dosage forms leading to the formation of 1-isonicotinyl-2-lactosylhydrazine (INH-Lac) (see Fig. 1) under high humidity storage conditions [10-15]. Besides, certain pharmacokinetic studies revealed that the fraction of INH bound to lactose could not be absorbed in humans after oral administration. It was also observed that this complex could not be converted into free isoniazid within the first 6 hours [11]. Therefore, this interaction could dramatically modify the bioavailability of orally administered isoniazid.

The purpose of this study was to develop and validate a new analytical method for the quantification of INH-Lac in oral solid dosage forms by UV-spectrophotometry. It is widely accepted that this kind of methods are less time-consuming in terms of preparation and analysis of samples and are cost effective than chromatographic methods. A rapid and easy technique is useful in the frame of stability studies as well as in quality control routine analysis of INH dosage forms containing lactose and lactose-derived excipients. The influence of several direct compression excipients on the specificity of the proposed analytical method has been also evaluated.

\section{Materials and methods}

\subsection{Materials}

Isoniazid was supplied by Guinama. 2,3-dichloro-1,4-naphthoquinone 98\% was purchased from Sigma (Sigma-Aldrich Química S.A.).

The following widely used excipients were selected: Tablettose ${ }^{\circledR}$ (Meggle Industries), Ludipress ${ }^{\circledR}$ and Povidone K-30 (BASF), A-TAB ${ }^{\circledR}$ (Rhodia Pharma), Pearlitol ${ }^{\circledR}$ and Neosorb ${ }^{\circledR}$ (Roquette), Explotab ${ }^{\circledR}$ and Lubritab $^{\circledR}$ (JRS Pharma) and Starch $1500^{\circledR}$ (Colorcon).

Milli $^{\circledR}-\mathrm{Q}$ water was used throughout all the experiments.

\subsection{Apparatus}

All spectral measurements were carried out with a conveniently calibrated UV-visible spectrophotometer (Beckman DU-6, BECKMAN INSTRUMENTS Inc., USA). In some reproducibility tests, a Beckman DU-7 UV-visible spectrophotometer was also used. 


\subsection{Solutions}

Ammonia-ammonium chloride buffer solution $\left(\mathrm{NH}_{3} / \mathrm{NH}_{4} \mathrm{Cl}, \mathrm{pH}=10.83\right)$ was prepared as described by the USP 26 procedures [16].

Phosphate buffer solution $\left(\mathrm{H}_{3} \mathrm{PO}_{4} / \mathrm{Na}_{2} \mathrm{PO}_{4} \mathrm{H}, \mathrm{pH}=6.10\right)$ was prepared as described by the USP 26 procedures [16].

2,3-dichloro-1,4-naphthoquinone solution. 2,3-dichloro-1,4-naphthoquinone was accurately weighed and diluted with absolute ethanol to give a theoretical quinone proportion of $0.034 \%(\mathrm{w} / \mathrm{V})$.

Lactose isonicotinoyl hydrazone standard was obtained as follows: a physical mixture was prepared with accurately weighed amounts of isoniazid $(50 \mathrm{mg})$ and $\alpha$-lactose monohydrate $(600 \mathrm{mg})$ by simple pulverisation and mixing of both solids. The mixture was then added in a 50-ml volumetric flask, diluted to volume with Milli-Q water and then magnetically stirred at $50 \mathrm{rpm}$, during 60 min keeping a temperature of $37^{\circ} \mathrm{C}$ by means of a thermostatic bath. After the solution was concentrated under vacuum (Savant Speed Vac ${ }^{\circledR}$-PD121P concentrator), $30 \mathrm{ml}$ of methanol were added to the crude product and the mixture was refrigerated overnight at $4^{\circ} \mathrm{C}$. The product was then filtered and dried. The TLC analysis of the hydrazone, according to the method reported by Bailey and Abdou [17], indicated an apparent purity of $99 \%$.

Isoniazid standard solution. An accurately weighed amount of isoniazid, was transferred into a $250 \mathrm{ml}$ volumetric flask and diluted to volume with $\mathrm{HCl} 0.1 \mathrm{~N}$ by sonication to obtain a concentration of $500 \mu \mathrm{g} / \mathrm{ml}$.

\subsection{Procedures}

Two spectrophotometric methods were designed for the determination of INH-Lac and free INH (effective in terms of absorption and hence pharmacologically active) in oral solid dosage forms. In the first one, a simultaneous determination of bound-to-lactose and not-bound isoniazid was carried out. The second one involved the production of a coloured substance between not-bound isoniazid and 2,3dichloro-1,4-naphthoquinone (Fig. 2).

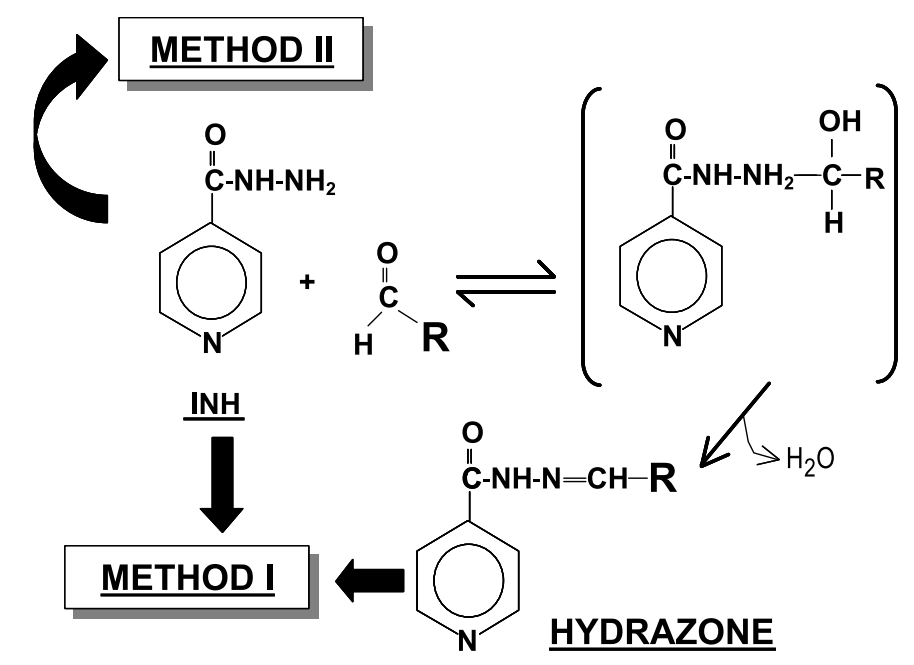

Fig. 2. Schematic view of the analytical methodology proposed for the determination of free INH. 


\section{Method I: Analysis of full isoniazid}

Isoniazid was dissolved in $0.1 \mathrm{~N} \mathrm{HCl}$ and, according to the obtained spectrum, it was measured at a maximum absorbance wavelength of $266 \mathrm{~nm}$ without interferences of the excipients selected for the different formulations in tablets.

\section{Method II: Analysis of active (free) isoniazid}

A lot of analytical methods have been proposed for the quantitative determination of isoniazid in pharmaceutical dosage forms. However, most of them are not specific for the hydrazide function and do not discriminate between an hydrazide and its hidrazone derivative. It has been reported that some hydrazides can develop several colours in alkaline solutions with 2,3-dichloro-1,4-naphtoquinone [18]. Due to the fact that a lot of degradation compounds structurally similar to INH could presumably be found in stability studies, a precise knowledge of the coloured compound obtained is essential. In this sense, reaction conditions such as, reagents concentration, $\mathrm{pH}$, time and temperature have been standardised. Briefly, $700 \mu \mathrm{l}$ of the isoniazid standard solution was placed onto a $25-\mathrm{ml}$ volumetric flask. $1 \mathrm{ml}$ of buffer solution and $6 \mathrm{ml}$ of 2,3-dichloro-1,4-naphtoquinone solution were added. The mixture was then diluted to volume with $\mathrm{Milli}^{\circledR}-\mathrm{Q}$ water. The reaction flask was placed in absence of light at $0^{\circ} \mathrm{C}$ during $40 \mathrm{~min}$ and then at a temperature of $25^{\circ} \mathrm{C}$ during $20 \mathrm{~min}$. After this period, a stable blue colour was developed. The blue product was extracted in n-amyl alcohol and lyophilized. The structure of the final compound was elucidated by atomic spectroscopy. It turned out to be 2-isonicotinoyl-3-amine-1,4-naphtoquinone. The same procedure was followed with a 500- $\mu$ lactose-isonicotinoyl-hydrazone solution and it was observed that the above-mentioned blue product was not formed. From these results, it was established that the background solution of the reaction should be 2,3-diamine-1,4-naphtoquinone at the same concentration of the samples. It was observed that the compound lactose-isonicotinoyl-hydrazone did not show any absorbance at wavelengths upper that $400 \mathrm{~nm}$, whereas the blue product obtained, 2-isonicotinoyl3-amine-1,4-naphtoquinone, showed a maximum absorbance at $610 \mathrm{~nm}$. Hence, free isoniazid can be assayed without any interference in the presence of bound lactose in complex mixtures.

\section{Results and discussion}

A previously described prospective validation protocol was applied for both analytical methods [19-21].

\subsection{Linearity}

The linearity was evaluated by linear regression analysis, which was calculated by the least square regression method. The calculated calibration curves proved to be linear in the range $2-30 \mu \mathrm{g} / \mathrm{ml}$ as can be seen in the most relevant linearity results showed in Table 1. Linearity plots yielded determination coefficients above 0.99 and good relative standard deviations of response factors (RRF) were obtained with both methods. No deviation from linearity was observed for both methods.

\subsection{Limits of detection and limit of quantification}

The parameters LOD and LOQ were determined on the basis of response and slope of the regression equation according with the ICH recommendations. As can be seen in Table 1, method I was found to be more sensitive. 
Table 1

Linear regression analysis resulting for absorbance vs. concentration data and relevant validation parameters: number of points $(n)$, relative standard deviation of response factors (RRF) as linearity indicator, limit of detection (LOD) and limit of quantification (LOQ) for both methods

\begin{tabular}{lcc}
\hline Parameter & Method I (full INH) & Method II (free INH) \\
\hline Concentration range $(\mu \mathrm{g} / \mathrm{ml})$ & $1.5-30.0$ & $0.5-30.0$ \\
$n$ & 30 & 30 \\
Intercept & 0.00473 & -0.00791 \\
Intercept's confidence interval $(95 \%)$ & {$[-0.00025-0.00970]$} & {$[-0.01700-0.00117]$} \\
Slope & 0.03686 & 0.05378 \\
Slope's confidence interval $(95 \%)$ & {$[0.03659-0.03712]$} & {$[0.05295-0.05460]$} \\
Determination coefficient $\left(r^{2}\right)$ & 0.999663 & 0.998437 \\
RRF & 2.23 & 4.67 \\
LOD $(\mu \mathrm{g} / \mathrm{ml})$ & 0.3568 & 0.0963 \\
LOQ $(\mu \mathrm{g} / \mathrm{ml})$ & 1.1892 & 0.3210 \\
\hline
\end{tabular}

\subsection{Precision}

The precision of both methods was determined by repeatability (intra-day) and intermediate precision. These parameters were studied assaying samples using three concentrations (low, medium and high) 3 replicates each. Repeatability was evaluated by assaying a set of samples ( $\mathrm{L}, \mathrm{M}$ and $\mathrm{H}$ ) during the same day. The intermediate precision was studied by comparing the effects of random events on the precision of both analytical procedures. Variations studied were day and equipment. Day-to-day repeatability was determined during two consecutive days and system-to-system repeatability was studied using two different previously calibrated equipments: a Beckman DU-6 and a Beckman DU-7 spectrophotometer. The results obtained (see Table 2) denoted a good repeatability for both methods with relative standard deviations below $2 \%$ for the three levels of concentration. System-to-system repeatability yielded also good results. In contrast, remarkable differences were found comparing the results obtained at different days for method II. This suggests that with this method, all samples must be assayed immediately and cannot be stored.

\subsection{Robustness}

The influence of the medium was studied for each method. For method I, $0.1 \mathrm{~N}$ hydrochloric acid or Milli-Q grade water were tested, whereas for method II, a $\mathrm{NH}_{3} / \mathrm{NH}_{4} \mathrm{Cl}$ buffer solution ( $\mathrm{pH}$ 10.83) or $\mathrm{H}_{3} \mathrm{PO}_{4} / \mathrm{Na}_{2} \mathrm{PO}_{4} \mathrm{H}$ ( $\mathrm{pH}$ 6.10) were compared in order to study the relevance of the $\mathrm{pH}$ value on the UV/Vis signal. Table 2 shows the RSD obtained at three different concentrations (L, M and $\mathrm{H}$ ) for each method and under the above-mentioned modifications. In view of the obtained results, it was proved that for method I the use of water or the acidic solution was not a relevant factor in terms of modification of the signal. In contrast, for method II remarkable differences of the relative standard deviation values were found. In this sense, it can be stated that for method II, the maintenance of the $\mathrm{pH}$ value is a factor of critical importance thorough the experiment.

\subsection{Accuracy}

Accuracy was determined for each method using $n=9$ determinations ( 3 concentrations, 3 replicates each). Statistical analysis was carried out by using Cochran's $G$ and Student's $t$-tests $(p=0.05)$. The 
Table 2

Main precision (repeatability and intermediate precision) and robustness results obtained at three different concentration levels: low, medium and high $(\mathrm{L} / \mathrm{M} / \mathrm{H})$

\begin{tabular}{lcc}
\hline Parameter & Method I (full INH) & Method II (free INH) \\
\hline $\begin{array}{l}\text { Response method RSD (M) (\%) } \\
\text { Repeatability (intra-day) }\end{array}$ & 1.09 & 1.52 \\
RSD (L) (\%) & 1.91 & 0.32 \\
RSD (M) (\%) & 0.56 & 1.33 \\
RSD (H) (\%) & 0.93 & 1.51 \\
System-to system repeatability & & \\
RSD (L) (\%) & 1.97 & 0.63 \\
RSD (M) (\%) & 0.21 & 1.11 \\
RSD (H) (\%) & 1.55 & 1.89 \\
Day-to-day repeatability & & \\
RSD (L) (\%) & 1.40 & 104.37 \\
RSD (M) (\%) & 0.44 & 56.95 \\
RSD (H) (\%) & 1.12 & 70.17 \\
Robustness (medium) & HCl $0.1 \mathrm{~N} /$ water & $10.83 / 6.10$ \\
RSD (L) (\%) & 2.04 & 21.26 \\
RSD (M) (\%) & 1.67 & 33.03 \\
RSD (H) (\%) & 1.92 & 48.06 \\
\hline
\end{tabular}

Table 3

Statistical analysis and accuracy results for both analytical methods

\begin{tabular}{lcc}
\hline Parameter & Method I (full INH) & Method II (free INH) \\
\hline Maximum variance & 0.053 & 0.058 \\
$G$ experimental & 0.792 & 0.508 \\
$G$ tabulated $(p=0.05, k=3, n=3)$ & 0.871 & 0.871 \\
$t$ experimental & 2.101 & 0.090 \\
$t$ tabulated $(p=0.05, k=3, n=3)$ & 2.306 & 2.306 \\
Average recovery $(\%)$ & 100.839 & 99.957 \\
RSD $(\%)$ & 1.20 & 1.43 \\
\hline
\end{tabular}

main resulting accuracy results are showed in Table 3. For both methods $G_{\text {experimental }}<G_{\text {tababulated }}$, what indicates that the variance values obtained at each concentration level are equivalent. Therefore, it can be concluded that the variable concentration does not have a statistically significant influence on the variability of both methods. The statistical Student- $t$ was also found to be below the tabulated values for all the recoveries obtained at different concentrations. These results denote that no statistically significant differences were found between $100.0 \%$ and the recoveries obtained for both methods. Average recoveries of INH for both methods are also showed in Table 3. All the calculated relative standard deviation values were found to be below $2 \%$.

\subsection{Specificity}

In order to asses the possible analytical applications of the proposed methods, the effect of commonly used excipients in the formulation of oral dosage forms was studied. A series of solutions containing INH and 10-fold concentration of each excipient were analysed in a range of wavelengths between 200 


\section{$\mathbf{A}(\mathbf{A U})$}

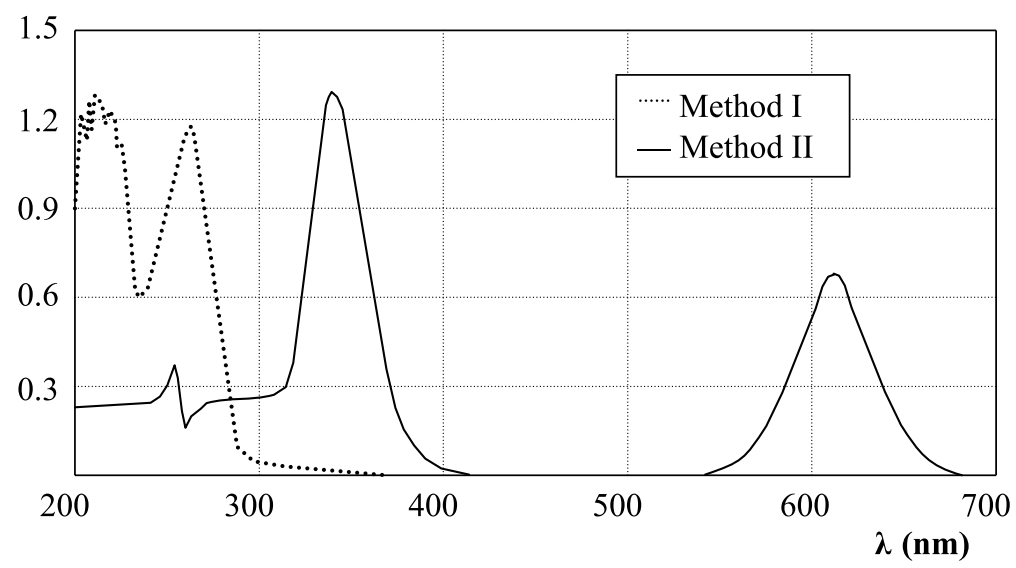

Fig. 3. UV/Vis spectrum of isoniazid. Solvents: Method I. 0.1 N hydrochloric acid. Method II. Milli-Q water.

Table 4

Recovery of $5 \mu \mathrm{g} / \mathrm{ml} \mathrm{INH} \mathrm{from} \mathrm{solutions} \mathrm{with} \mathrm{a} 50 \mu \mathrm{g} / \mathrm{ml}$ of some common excipients $(n=5)$

\begin{tabular}{lrr}
\hline Recovery (\%) & \multicolumn{1}{c}{ Method I } & Method II \\
\hline Tablettose ${ }^{\circledR}(\alpha$-lactose monohydrate) & $100.9( \pm 1.2)$ & $99.2( \pm 1.9)$ \\
Ludipress $^{\circledR}$ (lactose:crospovidone:povidone) & $100.1( \pm 0.9)$ & $100.8( \pm 1.4)$ \\
Povidone K-30 $^{\circledR}$ (povidone) & $99.9( \pm 3.1)$ & $99.4( \pm 2.7)$ \\
A-TAB $^{\circledR}$ (dicalcium phosphate anhydrous) & $100.5( \pm 2.7)$ & $99.1( \pm 3.1)$ \\
Pearlitol $^{\circledR}$ (mannitol) & $100.9( \pm 2.6)$ & $100.0( \pm 1.6)$ \\
Neosorb $^{\circledR}$ (sorbitol) & $100.4( \pm 1.9)$ & $98.9( \pm 2.7)$ \\
Explotab $^{\circledR}$ (sodium starch glycolate) & $101.0( \pm 2.1)$ & $99.7( \pm 0.1)$ \\
Lubritab $^{\circledR}$ (hydrogenated vegetable oil) & $99.2( \pm 1.6)$ & $101.9( \pm 2.3)$ \\
${\text { Starch } 1500^{\circledR} \text { (starch) }}$ & $100.3( \pm 0.4)$ & $101.3( \pm 1.7)$ \\
\hline
\end{tabular}

and $700 \mathrm{~nm}$. The spectrophotometric spectrum obtained for the two methods (see Fig. 3) did not differ from those obtained without excipients and no analytical interferences of placebos were found at the respectively maximum wavelength (Table 4 ).

\section{Conclusions}

In conclusion, the proposed method for the analysis of isonicotinoyl lactosyl-hydrazones and "free" INH in isoniazid oral formulations was successfully applied to the quantitative analysis of both products providing a fast and inexpensive method as an alternative to chromatographic methods.

The hereby described analytical methods constitute a useful tool for the assay of INH in orallyadministered pharmaceutical dosage forms, particularly in these formulations containing lactose as excipients (which is very common), in order to check the possible formation of non-absorbable hydrazones between INH and lactose.

It can be also concluded that the combination of both methods provides a specific, precise and sensitive way to study the interaction INH-lactose in the frame of the most commonly used stability studies. 


\section{References}

[1] A.I. El-Sony, Health Policy 75 (2006), 272-279.

[2] T.F. Brewera and S.J. Heymannb, Arch. Med. Res. 36 (2005), 617-621.

[3] http://www.hopkins-abxguide.org, 2006.

[4] American Thoracic Society/Centers for Disease Control and Prevention/Infectious Diseases Society of America, Am. J. Respir. Crit. Care Med. 167 (2003), 603-662.

[5] T.T. Mariappan, K.C. Jindal and S. Singh, J. Pharm. Biomed. Anal. 36 (2004), 905-908.

[6] T.T. Mariappan, T. Geetha, R. Pandey, K.C. Jindal and S. Singh, J. Pharm. Biomed. Anal. 36 (2004), 643-647.

[7] E. Hammam, A.M. Beltagi and M.M. Ghoneim, Microchem. J. 77 (2004), 53-62.

[8] E. Calleri, E. De Lorenzi, S. Furlanetto, G. Massolini and G. Caccialanza, J. Pharm. Biomed. Anal. 29 (2002), $1089-1096$.

[9] D. Córdoba-Díaz, M. Córdoba-Díaz, M. Córdoba-Borrego and J.M. Moreno Cerezo, Industria Farmacéutica 4 (2000), 93-98.

[10] M.B. Devani, C.J. Shishoo, K.J. Doshi and H.B. Patel, J. Pharm. Sci. 74(4) (1985), 427-432.

[11] M.B. Devani, C.J. Shishoo, M.A. Patel and D.D. Bhalara, J. Pharm. Sci. 67(5) (1978), 661-663.

[12] A. Carlin, N. Gregory and J. Simmons, J. Pharm. Biomed. Anal. 17(4/5) (1998), 885-890.

[13] A.G. Davidson, Analyst 107 (1982), 422-427.

[14] A.G. Butterfield, E.G. Lovering and R.W. Sears, J. Pharm. Sci. 69 (1982), 222-224.

[15] Y. Matsuki, Y. Katakuse, H. Matsuura, H. Kiwada and T. Goromaru, Chem. Pharm. Bull. 39(2) (1991), 445-448.

[16] United States Pharmacopeia 26th revision, USP 26/NF 21, Rockville, MD, USA, 2003.

[17] L.C. Bailey and H. Abdou, J. Pharm. Sci. 66(4) (1977), 564-567.

[18] J.A. Plaizier, J.G. Van Damme and R.E. De Nève, Anal. Chem. 48(11) (1976), 1536-1538.

[19] M. Castro, S. Gascón, M. Pujol, J.M. Sans and L. Vicente, Validación de Métodos Analíticos, A.E.F.I., Madrid, 1989.

[20] M. Córdoba-Borrego, M. Córdoba-Díaz and D. Córdoba-Díaz, J. Pharm. Biomed. Anal. 18 (1999), 919-926.

[21] International Conference of Harmonization, The European Agency for the Evaluation of Medical Products. Note for Guidance on Validation of Analytical Procedures: Methodology, ICH Topics Q 2A, 2005. 


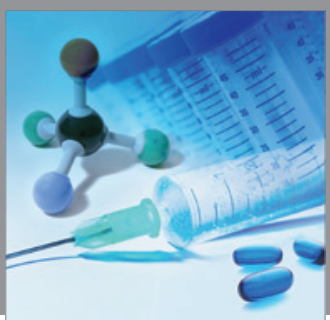

International Journal of

Medicinal Chemistry

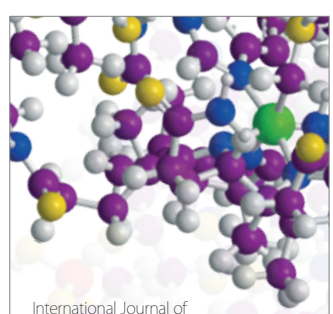

Carbohydrate Chemistry

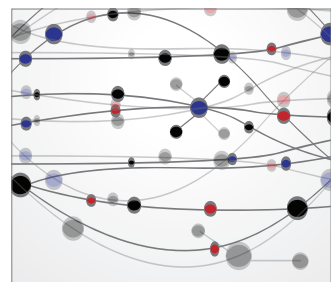

The Scientific World Journal
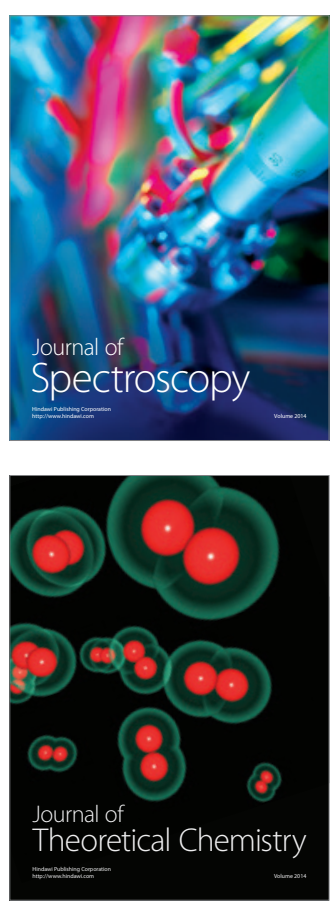
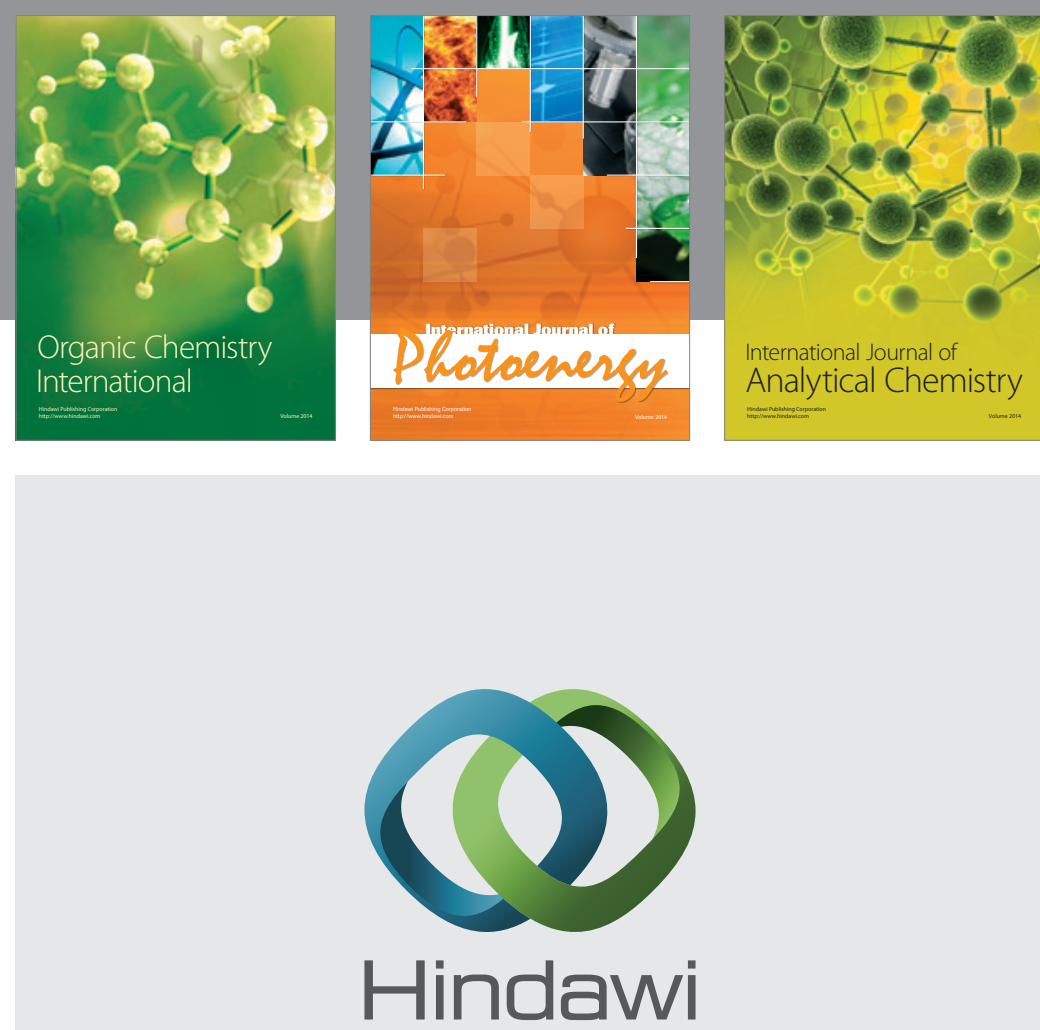

Submit your manuscripts at

http://www.hindawi.com
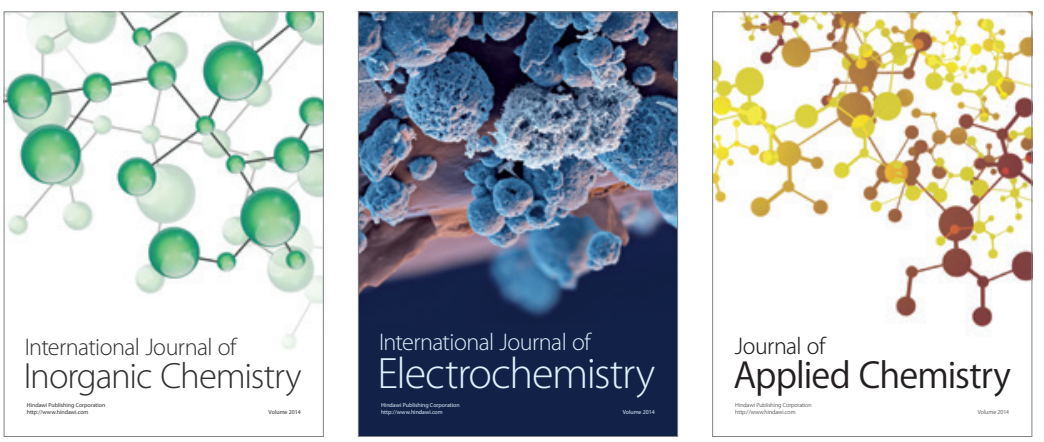

Journal of

Applied Chemistry
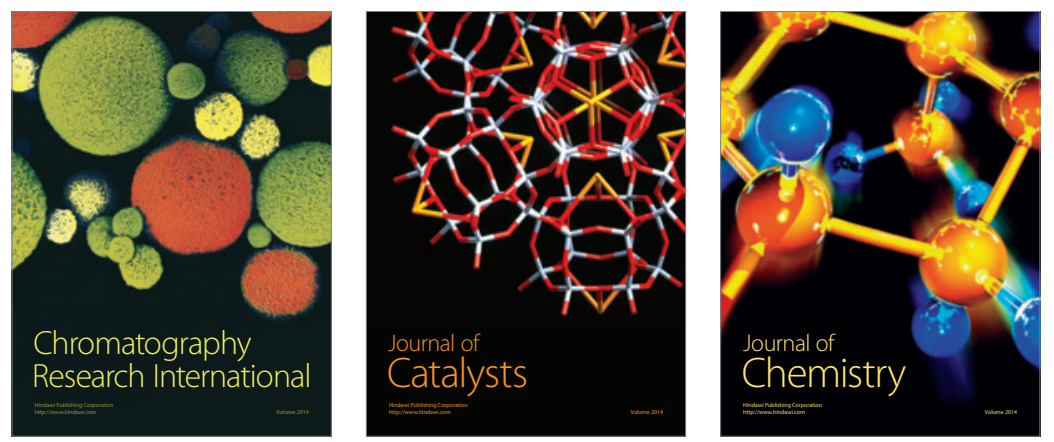
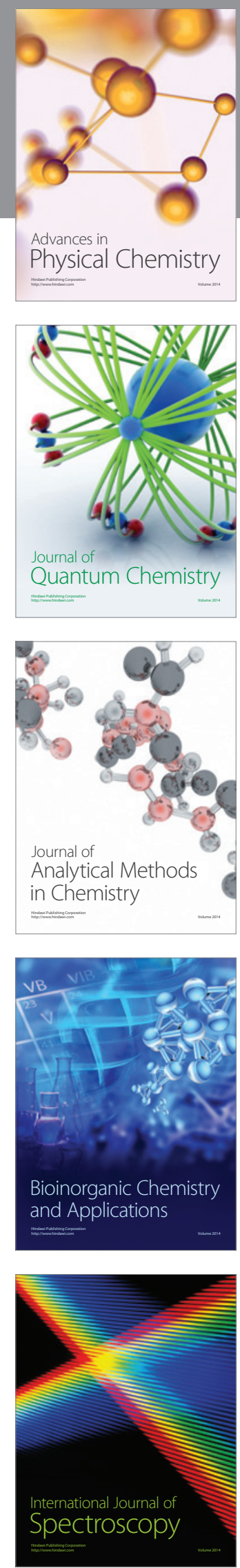